\title{
Peer Effects on Weight Status, Dietary Behaviour and Physical Activity among Adolescents in Europe: Findings from the I.Family Study
}

Wencke Gwozdz, Peng Nie, Alfonso Sousa-Poza, Stefaan DeHenauw, Regina Felső, Antje Hebestreit, Isabel Iguacel, Lauren Lissner, Fabio Lauria, Angie Page, Lucia A. Reisch, Michael Tornaritis, Toomas Veidebaum, Garrath Williams and Ronja Foraita*

\begin{abstract}
SUMMARY
This study uses survey data from the I.Family Study to investigate the association between adolescent and peer overweight in a sample of adolescents aged 12-16 from six European countries. We find clear evidence of peer effects on body mass index, waist circumference and body fat, which are stronger among adolescents at the upper end of overweight distribution. We also provide evidence that both consumption of less healthy foods and time spent in leisure time physical activity and audio-visual media are positively associated with similar behaviours among friends. These observations may suggest that peer effects on adolescent overweight operate by influencing friends' behaviour patterns, especially unhealthy food consumption and physical (in)activity.
\end{abstract}

\footnotetext{
* Wencke Gwozdz: Institute of Household Sciences, Justus-Liebig-University, Giessen, Germany, Email: wencke.gwozdz@fb09.uni-giessen.de and Department of Intercultural Communication and Management, Centre for Corporate Social Responsibility, Copenhagen Business School, Frederiksberg, Denmark. Email: wg.ikl@cbs.dk. Peng Nie (corresponding author): School of Economics and Finance, Xi'an Jiaotong University, Xi'an, China. Email: niepeng2017@mail.xjtu.edu.cn. Alfonso Sousa-Poza: Institute for Health Care \& Public Management, University of Hohenheim, Stuttgart, Germany. Email: alfonso.sousa-poza@uni-hohenheim.de. Stefaan DeHenauw: Department of Public Health, Faculty of Medicine and Health Sciences, University Hospital, Ghent University, Ghent, Belgium. Email: stefaan.dehenauw@ugent.be. Regina Felső: Department of Paediatrics, Medical Faculty, University of Pécs, Pécs, Hungary. Email: felso.regina@pte.hu. Antje Hebestreit: Leibniz Institute for Prevention Research and Epidemiology - BIPS, Bremen, Germany. Email: hebestr@leibniz-bips.de. Isabel Iguacel: Growth, Exercise, Nutrition and Development Research Group, University of Zaragoza, Zaragoza, Spain. Email: iguacel@unizar.es. Lauren Lissner: Department of Public Health and Community Medicine, Public Health Epidemiology Unit, Sahlgrenska Academy, University of Gothenburg, Gothenburg, Sweden. Email: lauren.lissner@gu.se. Fabio Lauria: Institute of Food Science \& Technology, National Research Council, Avellino, Italy. Email: fabio.lauria@isa.cnr.it. Angie Page: School for Policy Studies, University of Bristol, Bristol, United Kingdom. Email: a.s.page@bristol.ac.uk. Lucia A. Reisch: Department of Intercultural Communication and Management, Centre for Corporate Social Responsibility, Copenhagen Business School, Frederiksberg, Denmark. Email: 1r.ikl@cbs.dk. Michael Tornaritis: Research and Education Institute of Child Health, Strovolos, Cyprus. Email: tor.michael@cytanet.com.cy. Toomas Veidebaum: National Institute for Health Development, Tervise Arengu Instituut, Tallinn, Estonia. Email: toomas.veidebaum@tai.ee. Garrath Williamsm: Department of Politics, Philosophy and Religion, University of Lancaster, Lancaster, United Kingdom. Email: g.d.williams@lancaster.ac.uk. Ronja Foraita: Leibniz Institute for Prevention Research and Epidemiology - BIPS, Bremen, Germany. Email: foraita@leibniz-bips.de. The usual disclaimer applies.

This work was done as part of the IDEFICS (http://www.idefics.eu) and I.Family studies (http://www.ifamilystudy.eu/). We gratefully acknowledge the financial support of the European Commission within the Sixth RTD Framework Programme Contract No. 016181 (FOOD), and the Seventh RTD Framework Programme Contract No. 266044. We would like to thank the editor David Stadelmann and two anonymous referees for valuable comments on an earlier version of this paper.
} 


\section{INTRODUCTION}

At a time when around 2.8 million annual deaths in the European Union (EU) result from the consequences of overweight and obesity and around 7\% of national health budgets are spent each year on obesity-linked diseases (European Commission, 2014), the prevalence of paediatric overweight or obesity is of particular concern (Ahrens et al., 2014). In EU countries, approximately 22 million children and "tweens" (i.e., children aged 10-12 years) are considered overweight or obese, with the numbers growing by 400,000 annually (European Commission, 2013). According to 2010 estimates from the World Health Organization's Childhood Obesity Surveillance Initiative (The World Health Organization Regional Office for Europe, 2010), around one in three children aged 6-9 years in the EU is overweight or obese. These overweight/obese children are expected to face an increased prevalence of chronic diseases such as cardiovascular disease, strokes, type 2 diabetes and a subset of cancers (Hill and Peters, 1998), as well as certain social and mental health risks (OECD, 2012).

One important aspect of obesity among children, adolescents and even adults is whether it is influenced by the behaviour patterns and/or diets of peers, a question addressed by much recent literature in economics and other disciplines (Asirvatham et al., 2014; Christakis and Fowler, 2007; Cohen-Cole and Fletcher, 2008; de la Haye et al., 2011a; Gwozdz et al., 2015; Halliday and Kwak, 2009; Larson et al., 2013; Nie et al., 2015; Trogdon et al., 2008). A greater understanding of potential peer effects on obesity could increase the efficacy of targeted policies and boost the potential benefits of interventions through the so-called social multiplier mechanism (Fletcher, 2011), i.e. policies could benefit from the externality inherent in peer effects. It is primarily this social multiplier effect that has been of interest to economists. Should such an effect exist, then it would amplify any shock that affects individual behaviour as the sum of the individual effects would then be enhanced by the peer effect related to the social interactions (Fortin and Yazbeck, 2015). Numerous public policies aimed at combating obesity (including restrictions on food marketing to children, food labelling, information campaigns, taxes and subsidies) would benefit from such an externality. Currently, there is much debate on public policies that influence prices of unhealthy foods, especially through taxation. As long as a certain individual behavior gives rise to a negative externality that may lead to obesity within a social network, it may be justified to introduce a tax on this behavior - and the magnitude of the tax would depend on the size of the peer effect (Fortina and Yazbeck, 2015). A more general economic justification for analyzing peer effects is that the economic costs 
associated with obesity are considered to be very high (Tremmel et al., 2017). In a comprehensive study for Germany, Lehnert et al. (2015) estimate the direct and indirect costs of overweight and obesity to approximately $€ 18$ billion in 2008 , which also represented a $70 \%$ increase in costs within six years when compared to a similar earlier study (Konnopka et al., 2011). This increase is directly related to the rising prevalence of obesity. An important characteristic of peer effects is that they not only propagate unhealthy behavior within a social network (and thereby increase obesity rates), peer effects can also change societal perceptions of an ideal body weight (Gwozdz et al., 2015). Such changing perceptions may give rise to a persistency of high obesity rates.

Unfortunately, the existing literature on peer effects in adolescence is strongly dominated by U.S. studies, and we need to be cautious in generalizing these across diverse cultures and institutional settings (Gwozdz et al., 2015). European studies are limited and the potential mechanisms through which peer effects operate on individual weight status remain largely underexplored. To begin addressing this gap, we use survey data from the I.Family Study to test for peer effects on body fatness in a sample of adolescents aged 12-16 in six European countries. Unlike Gwozdz et al. (2015), our study identifies peer effects based on unique information about individuals that adolescents specifically designate as their friends. Because such a proximal definition of peers probably operates by influencing diet behaviour and physical activity (Trogdon et al., 2008), we explore the underlying mechanisms of peer effects on adolescents' bodyweight using a rich set of measures that identify dietary patterns (e.g. the Youth Healthy Eating Index (YHEI), consumption frequency of less and more healthy foods and time spent on leisure time physical activity (PA) and audio-visual media (AVM)). We define less healthy foods as sugar sweetened beverages (SSBs), simple sugars, fatty foods, and fast foods eaten as meals contrasting these with healthy foods like vegetables, fruits and other fibre-rich foods.

The contribution of our analysis to the literature on peer effects is twofold: first, it is one of the few European studies that focuses on peer effects of obesity among adolescence - and the only one to our knowledge that addressed the possible mechanisms through which the peer effect works within this population group. Second, our study uses a collection of objective measures on obesity, which few studies have at their disposal. As we highlight in the next section, having such rich objective data is important in order to credibly identify peer effects.

Overall, our results identify an association between adolescents' and their peers' overweight irrespective of whether the measure is body mass index (BMI), waist circumference or body 
fat. Conditional quantile regressions show that this association is strongly at and above the conditional bodyweight distribution median, especially for BMI and body fat. Interestingly, however, although we find clear evidence of a positive association between adolescent consumption of less healthy foods and peer consumption of similar foods, we find no such association for the consumption of healthy foods. Furthermore, adolescents' time spent on both leisure time PA and AVM is positively correlated with the time spent on those activities by their friends. Taken together, these findings suggest that peer effects on adolescent overweight operate through shared patterns of behaviour, particularly unhealthy food consumption and PA behaviour.

The remainder of the paper is structured as follows: Section 2 reviews the relevant research, Section 3 documents the data and methodology, Section 4 reports the results and Section 5 concludes the paper.

\section{PRIOR RESEARCH}

Since Christakis and Fowler's (2007) seminal paper, quite a large body of literature has evolved that investigates peer effects (see Table 1). Yet although a broad body of literature exists on the relation between peer effects and individual bodyweight, this research is dominated by studies based on U.S. data (Asirvatham et al., 2014; Christakis and Fowler, 2007; Cohen-Cole and Fletcher, 2008; de la Haye et al., 2011a; Fortin and Yazbeck, 2015; Fowler and Christakis, 2008; Halliday and Kwak, 2009; Larson et al., 2013; Leatherdale and Papadakis, 2009; O'Malley et al., 2014; Renna et al., 2008; Trogdon et al., 2008; Valente et al., 2009; Yang and Huang, 2013). We are aware of only three recent studies that examine this topic in Europe (Gwozdz et al., 2015; Mora and Gil, 2013; Quinto Romani, 2014). Mora and Gil (2013) use data from a sample of secondary school students in Catalonia, Spain. They identify a positive and significant causal relation between adolescent BMI and friends' average BMI and also find that these peer effects are stronger than those reported for the U.S. Quinto Romani (2014) draws on a longitudinal data set from state schools in Aalborg, Denmark, and demonstrates that a targeted health intervention not only has a beneficial effect on the BMI of the individuals involved but also on that of peers not exposed to the intervention. This suggests peer health spill-over effects occur in a school setting. Gwozdz et al. (2015) use data from IDEFICS ("Identification and prevention of Dietary- and lifestyle-induced health EFfects In Children and infantS") to show that although same-gender peer effects exist among the approximately 14,000 children aged 2-9 from 16 regions of 8 European countries, they differ by both region 
and the measure of overweight employed. For instance, peer effects are stronger in the more collective regions of Spain, Italy and Cyprus.

Table 1

Summary of studies of peer effects on individual bodyweight

\begin{tabular}{|c|c|c|c|c|c|c|}
\hline Authors (year) & Data source & Country & Targets & $\begin{array}{c}\text { Peer } \\
\text { definition }\end{array}$ & Methods & Outcomes \\
\hline $\begin{array}{l}\text { Christakis and } \\
\text { Fowler (2007) }\end{array}$ & $\begin{array}{l}\text { Framingham } \\
\text { Health Study }\end{array}$ & U.S. & Adults & $\begin{array}{c}\text { Self- } \\
\text { nominated } \\
\text { friends, } \\
\text { siblings, } \\
\text { spouse, and } \\
\text { neighbors }\end{array}$ & LLM & Positive \\
\hline $\begin{array}{l}\text { Cohen-Cole and } \\
\text { Fletcher (2008) }\end{array}$ & Add Health & U.S. & Adolescents & $\begin{array}{l}\text { Self- } \\
\text { nominated } \\
\text { friends }\end{array}$ & $\begin{array}{l}\text { OLS } \\
\text { Logit }\end{array}$ & Positive \\
\hline Renna et al. (2008) & Add Health & U.S. & Adolescents & $\begin{array}{l}\text { Self- } \\
\text { nominated } \\
\text { friends }\end{array}$ & OLS/IV & Positive \\
\hline $\begin{array}{l}\text { Trogdon et al. } \\
(2008)\end{array}$ & Add Health & U.S. & Adolescents & $\begin{array}{c}\text { Self- } \\
\text { nominated } \\
\text { friends; } \\
\text { Students } \\
\text { within the } \\
\text { same grade }\end{array}$ & $\begin{array}{c}\text { OLS/TSLS } \\
\text { Probit/TSLS-Probit QR }\end{array}$ & Positive \\
\hline $\begin{array}{l}\text { Fowler and } \\
\text { Christakis (2008) }\end{array}$ & Add Health & U.S. & Adolescents & $\begin{array}{l}\text { Self- } \\
\text { nominated } \\
\text { friends }\end{array}$ & OLS/FE/MC & Positive \\
\hline $\begin{array}{l}\text { Halliday and Kwak } \\
\text { (2009) }\end{array}$ & Add Health & U.S. & Adolescents & $\begin{array}{l}\text { Self- } \\
\text { nominated } \\
\text { friends }\end{array}$ & OLS/Probit/FE & Positive \\
\hline $\begin{array}{l}\text { Valente et al. } \\
\text { (2009) }\end{array}$ & $\begin{array}{l}\text { In-school } \\
\text { survey, Los } \\
\text { Angeles }\end{array}$ & U.S. & $\begin{array}{l}\text { Adolescents } \\
(11-15 \mathrm{yrs})\end{array}$ & $\begin{array}{l}\text { Self- } \\
\text { nominated } \\
\text { friends }\end{array}$ & RE-Logistic/ERGM & Positive \\
\hline $\begin{array}{l}\text { Yakusheva et al. } \\
\text { (2011) }\end{array}$ & $\begin{array}{c}\text { The study from } \\
\text { a private } \\
\text { Midwestern } \\
\text { university }\end{array}$ & U.S. & $\begin{array}{l}\text { Female } \\
\text { freshmen }\end{array}$ & Roommates & NE & Negative \\
\hline
\end{tabular}


$\begin{array}{ll}\text { The study from } \\ \text { Yakusheva et al. } & \text { two universities }\end{array}$

(2014)

Larson et al.

(2013)

Yang and Huang (2013)

$\begin{array}{lc}\text { Asirvatham et al. } & \text { Arkansas } \\ \text { (2014) } & \text { Center for } \\ \text { Health }\end{array}$
Improvement

A public highDe la Haye et al. school survey (2011)

in a major Australian city

Leatherdale and

Papadakis (2011)

Mora and Gil

(2013)

Loh and Li (2013)

SHAPES

A secondaryschool student survey,

Catalonia
U.S $\begin{gathered}\text { First-year } \\ \text { college } \\ \text { students }\end{gathered}$

Self-

nominated friends

Self-

U.S. Adolescents nominated friends

Students within the same grade

U.S.
(Arkansas)

Children

$\mathrm{OLS} / \mathrm{FE} / \mathrm{RE}$

Positive

Self-

Australia Adolescents

nominated

SAOMs

No effects

Canada

Adolescents

Senior

students

(grades 11

and 12)

within the

same school

Logistic

Positive

Self-

Adolescents (14-18 yrs)

nominated friends within the same classroom

OLS/GMM/LIML Positive

Children in the same age group, level of school and community; Children in the same age group and community

OLS/2SLS/QR Positive 


\begin{tabular}{|c|c|c|c|c|c|c|}
\hline $\begin{array}{l}\text { Gwozdz et al. } \\
\text { (2015) }\end{array}$ & IDEFICS & $\begin{array}{c}\text { Eight } \\
\text { European } \\
\text { countries }\end{array}$ & $\begin{array}{c}\text { Children }(2-9 \\
\text { yrs })\end{array}$ & $\begin{array}{l}\text { the same } \\
\text { age group, } \\
\text { in the same } \\
\text { school }\end{array}$ & OLS/FE & Positive \\
\hline $\begin{array}{l}\text { Quinto Romani } \\
\text { (2014) }\end{array}$ & $\begin{array}{c}\text { A longitudinal } \\
\text { data of } \\
\text { schoolchildren }\end{array}$ & $\begin{array}{l}\text { Aalborg, } \\
\text { Denmark }\end{array}$ & $\begin{array}{l}\text { Adolescents } \\
\text { (11-13) }\end{array}$ & $\begin{array}{l}\text { Children in } \\
\text { the same } \\
\text { school }\end{array}$ & DID & Positive \\
\hline Nie et al. (2015) & CHNS & China & $\begin{array}{c}\text { Children (3-9) } \\
\text { and } \\
\text { adolescents } \\
(10-18)\end{array}$ & $\begin{array}{l}\text { Children in } \\
\text { the same } \\
\text { age group } \\
\text { and } \\
\text { community }\end{array}$ & OLS/QR/GMM/LIML/FE & Positive \\
\hline $\begin{array}{l}\text { Fortin \& Yazbeck } \\
\text { (2015) }\end{array}$ & Add Health & U.S. & Adolescents & $\begin{array}{c}\text { Self- } \\
\text { nominated } \\
\text { friends }\end{array}$ & OLS/NLS/GMM & Positive \\
\hline
\end{tabular}

Notes: Based on Nie et al. (2015). Add Health = the National Longitudinal Study of Adolescent Health; EAT = the Eating and Activity in Teens in 2010; and SHAPES = the School Health Action, Planning, and Evaluation System. IDEFICS = Identification and prevention of Dietary - and lifestyle - induced health EFfects In Children and InfantS. The estimation methods are as follows: Logistic=logistic model; LLM=longitudinal logistic-regression model; Ologit=ordered logit model; Probit $=$ probit model; TSLS $=$ two stage least squared model; IV-Probit= instrumental variable probit model; RE-Logistic= random effects logistic model; ERGM= exponential random graph model; SAOMs=stochastic actor-oriented model; FE=fixed effects model; $\mathrm{RE}=$ random effects model; $\mathrm{MC}=$ Monte Carlo simulations; $\mathrm{DID}=$ difference-in-difference; $\mathrm{QR}=\mathrm{quantile}$ regression model; $\mathrm{NE}=$ natural experiment method (using random roommate assignments); NLS= non-linear least squares; $\mathrm{GMM}=$ general method of moments model; LIML=limited information maximum likelihood model; and $\mathrm{MR}=$ mean regression.

Most such research, however, fails to explore the potential pathways of peer effects on individual bodyweight - that is, whether peer effects operate through dietary or physical activity patterns, or by other channels such as perceptions/norms of body weight. There is some evidence that peers can influence perceptions of an ideal body weight or composition. For instance, Ali et al. (2011b), using data from Wave II (1996) of the U.S. National Longitudinal Survey of Adolescent Health (NLSAH), suggest that adolescents aged 11-20 who are exposed to heavier peers and overweight/obese parents are more likely to underestimate their own weight status. Likewise, Maximova et al. (2008), using data from the Quebec Child and Adolescent Health and Social Survey, show not only that a higher parental and schoolmate BMI is linked with greater underestimation of weight status among children and adolescents but that overweight and obese youth are more likely to underestimate their own weight relative to non-overweight peers. This latter is echoed by Gwozdz et al. (2015), whose analysis indicates that parental underestimation of their own children's weight go hand in hand with 
fatter peer groups among the children. Similarly, Blanchflower et al. (2009) demonstrate that self-perception of overweight is affected by an individual's BMI relative to a broadly defined peer group. ${ }^{1}$ However, evidence as to whether and how peers may affect dietary behaviours and especially physical activity is scant (Salvy et al., 2012). One interesting exception is Fortin and Yazbeck's (2015) analysis of four waves from the Add Health survey of American adolescents in grades 7 through 12, which identifies positive (albeit small) peer effects on fast food consumption among adolescents within the same school friendship network.

Unfortunately, almost all the above studies use BMI as a measure of overweight, and the majority rely on self-reported measures (most notably, from the NLSAH), both of which are considered problematic. Many criticize the reliability of BMI as a proxy of individual fat on the basis of its inability to distinguish fat from muscle, bone and other lean body mass (Barlow, 2007; Burkhauser and Cawley, 2008; Gallagher et al., 1996; McCarthy et al., 2006; RomeroCorral et al., 2006; Wellens et al., 1996; Yusuf et al., 2005). In addition, epidemiologists disparage self-reported weight and height data because of the potential for reporting biases (Huybrechts et al., 2006; Shields et al., 2011).

This paper therefore contributes to the literature in two important respects: First, it analyses potential peer effects on a range of objective measures of body overweight. Second, it explores the specific mechanisms through which peers might influence adolescent body overweight by assessing peer effects on obesogenic behaviours (diet, physical activity and sedentary behaviours).

\section{DATA AND METHODS}

\section{Survey and sample}

Our data are taken from the I.Family Study, a 2013/2014 follow-up to the IDEFICS cohort and intervention study (Ahrens et al., 2017). I.Family covers not only the children from the original IDEFICS cohort but also their siblings and newly recruited children. It was designed to assess the interplay between complex lifestyle, social, behavioural and genetic factors and their impact on dietary habits and health outcomes, and one strength of this survey lies in its detailed information on body fatness. Trained field staff measured skinfolds, waist and hip circumference, bioelectrical impedance and ultrasonography as well as height and weight,

\footnotetext{
${ }^{1}$ Here relative BMI is measured as an individual's BMI divided by the averaged BMI from their country, age band and gender cell (Blanchflower et al., 2009).
} 
giving us several measures of body composition. They also took venous blood and mouth mucosal cell DNA from particular sub-samples to collect biochemical and gene expression markers.

To compile our analytic sample of 12- to 16-year-olds from Cyprus, Estonia, Germany, Hungary, Italy, and Sweden, we selected only those subjects for whom detailed information is available on demographic, parental and household characteristics and on designated friends (Arvidsson et al., 2015). This leaves a final sample of 655 observations for BMI, 646 observations for waist circumference, and 646 observations for body fat.

\section{Peers}

Peers are identified based on an item in the written self-administered survey that asks respondents to provide the names and grade/class of up to 10 friends and indicate the closeness of the friendship (see Appendix A1). A second step then identifies friends who are also participating in the I.Family Study, after which all data are anonymized. By including only these participating friends in our sample, we ensure a rich data set of matching information.

\section{Dependent variables}

Weight status measures. Our analysis is based on three measures to derive level of overweight/overfatness measures: (i) BMI $z$-values calculated using International Obesity Task Force (IOTF) growth charts (Cole et al., 2000) ${ }^{2}$, (ii) waist circumference $z$-values calculated based on IOTF growth charts, and (iii) body fat estimated by a composite measure developed using field-derived data on hip circumference, triceps skinfold and resistance (measured with bioelectrical impedance analysis), together with $z$-values for body fat based on IOTF growth charts. As in (Gwozdz et al., 2013), our choice of methods is determined largely by Bammann et al.'s (2013) validation of the obesity measures in the IDEFICS study.

Diet. Dietary patterns are measured by the self-administered food frequency questionnaire (FFQ) section of the Children's Eating Habits Questionnaire (CEHQ) (Arvidsson et al., 2015), which asks adolescents about specific consumption frequencies of 59 food and beverage categories. The I.Family version of the CEHQ-FFQ is comparable to its previous version, a reproducible and validated instrument used during the IDEFICs study (Bel-Serrat et al., 2013; Huybrechts et al., 2011; Lanfer et al., 2011). In I.Family, all 59 items are based on the question,

\footnotetext{
${ }^{2}$ We use the IOTF growth charts which is the common approach when using international data, i.e. data from several countries. The thresholds for classifying children are derived from a reference population. The IOTF thresholds are derived from body mass index data from six large, nationally representative, cross-sectional surveys from Brazil, Great Britain, Hong Kong, the Netherlands, Singapore, and the United States (see Cole et al., 2000).
} 
"In the last month, how many times did you eat or drink the following food items?" with response categories coded as follows: $1=$ never/less than once a week, $2=1-3$ times a week, $3=4-6$ times a week, $4=1$ time per day, $5=2$ times a day, $6=3$ times a day and $7=4$ or more times a day. We recode these categories to capture weekly consumption and then use the category mid-point as a proxy for weekly consumption frequency $(1=0,2=2,3=5,4=7,5$ $=14,6=21$ and $7=30$ ). We define unhealthy food consumption as the consumption of sugarsweetened beverages (SSBs), simple sugar foods (sugar), ${ }^{3}$ fatty foods (fat) ${ }^{4}$ and fast foods eaten as meals. Healthy food consumption includes consumption of vegetables and fruits (vegetables) ${ }^{5}$ and other fibre rich foods (fibre). ${ }^{6}$ Comparability across countries was ensured in the original survey by the same foods and beverages being translated into national languages (Arvidsson et al., 2015). The CEHQ-FFQ measures fast food consumption based on the question, "How many times do you consume a full meal alternative to a main meal (breakfast, lunch, dinner) in a fast food restaurant?", measured on a 5-point scale from $1=$ never to $5=3$ or more times a week. We calculate the other food consumption indicators by adding corresponding food categories from the CEHQ-FFQ.

As a further measure of healthy eating, we introduce the 100-point Youth Healthy Eating Index (YHEI) (Feskanich et al., 2004), on which a higher score indicates a healthier diet. Our data set enable to replicate 10 of the 13 original YHEI dimensions, seven designed to measure food consumption and three to identify food-related behavioural patterns, as follows: (1) whole grains (source of fibre, vitamins and minerals), (2) vegetables (source of vitamins and minerals), (3) fruits (source of vitamins), (4) dairy (source of calcium), (5) snack foods (unnecessary energy), (6) soda and drinks (unnecessary energy), and (7) margarine and butter (sources of fat), (8) fried foods outside home (high energy intake), (9) eat breakfast (indicator of healthy dietary patterns) and (10) dinner with the family (indicator of healthy dietary patterns). We calculate scores for each based on the criteria proposed by Feskanich et al. (Feskanich et al., 2004), and then sum all available scores for the 10 dimensions.

Physical activity and sedentary behaviours. We measured self-reported time spent outdoors in leisure time using the following question: "How much time do you spend playing or "hanging out' outdoors on a typical day in your leisure time?". This was reported separately for both

\footnotetext{
${ }^{3}$ The sugar indicator comprises fruit juices, sugar sweetened drinks, sweetened or sugar added breakfast cereals and muesli, sweetened and/or flavoured milk and yoghurt, sweet snacks and ice cream and jams and honey.

${ }^{4}$ Fatty food consumption covers fried potatoes, fried fish, fried meat, fried or scrambled eggs.

${ }^{5}$ The indicator vegetables and fruits refers to potatoes and other cooked vegetables, legumes, raw vegetables, and fresh fruits with and without added sugar.

${ }^{6}$ Fibre consumption includes potatoes and other cooked vegetables, legumes, raw vegetables, fresh fruits with and without added sugar, wholemeal bread, pasta, noodles, rice and other cereals, nuts, seeds and dried fruits, as well as porridge, oatmeal, gruel, unsweetened cereals and plain muesli.
} 
weekday and weekend day and combined for our analytic measure into total amount of time (in hours) spent on leisure time PA per week. We also measured time spent in audio visual sedentary behaviours (audio visual media - AVM) by the questions: "How much time do you spend watching TV shows, movies or music videos?" Time (hours per week) spent either watching TV or using a personal computer/laptop (with/without Internet access) was the measure used in the analysis.

\section{Control variables}

Following the extant literature of peer effects on individual bodyweight (e.g. Gwozdz et al., 2015; Mora and Gil, 2013), we examined a series of control variables comprising characteristics of the individual adolescents, of his or her mother and family. The adolescent characteristics comprise six variables: age, sex, meal frequency (times a day), health-related quality of life (KINDL), number of I.Family Study friends and time spent with these friends. Sex is a dummy equal to 1 if the adolescent is male and 0 otherwise. Health-related quality of life is based on the Questionnaire for Measuring Health-Related Quality of Life in Children and Adoloescents KINDL - an instrument that has been tested in 13 European countries and turned out to be cross-culturally valid (Ravens-Sieberer et al., 2008). The instrument includes four dimensions: emotional wellbeing, self-esteem, parent relations and social contacts. The sum score of all items ranges from 0 to 64 , with a higher score denoting a better quality of life (Bullinger et al., 2008). Time spent with friends is measured on a scale from 1 = "a lot of" time to 5 = "some" time. We also introduce four mother and family characteristic variables: mother's age, occupational status, BMI and household income. Mother's occupational status is measured on a 6 -point scale of $1=$ not employed, $2=$ full time, $3=$ part time $\geq 15$ hours a week, $4=$ part time $\leq 15$ hours a week, $5=$ on leave and $6=$ in education. We recode this score as a dummy with "not employed" as the reference category. We similarly convert the household income scale of 1 = low level, 2 = low-medium level, 3 = medium level, 4 = medium-high level and 5 $=$ high level to a dummy with "low level" as the reference group.

\section{Estimation strategies}

Ordinary least squares $(O L S)$. To test for the existence of peer effects on adolescent's weight status based on the three $z$-scores for BMI, waist circumference and body fat, we estimate the following OLS model: 


$$
T_{i}=\beta_{0}+\beta_{1} P_{i}+\beta_{2} X_{i}+\beta_{3} M_{i}+\beta_{4} F+\beta_{5} C+\varepsilon_{i}
$$

where $T_{i}$ denotes the overweight measures of adolescent $i$, and $P_{i}$ represents the corresponding average overweight measure of the adolescent's designated friends. $X_{i}$ is a vector of adolescent $i$ 's characteristics, and $M_{i}$ is a vector of adolescent $i$ 's mother's characteristics. $F$ denotes the family characteristic in form of household income dummies, $C$ is a country dummy, $\beta_{1}$ is the key coefficient of interest, and $\varepsilon_{i}$ is the error term.

Multilevel mixed-effects generalized linear model (MMGLM). We then control for contextual effects such as shared environments by employing the following multilevel mixed-effects generalized linear model. MMGLM allows taking care of the data structure, i.e., individuals as first level and country as second-level random effect:

$$
T=\beta X+\gamma Z+\varepsilon
$$

where $T$ is a column vector of adolescent's overweight, $X$ is a matrix of the predictor variables for fixed effects and $\beta$ is a column vector of the fixed-effects regression coefficients. $Z$ is a matrix of random effects, $\gamma$ is a vector of random effects (here, the random complement to the fixed-effects coefficient $\beta), \varepsilon$ is a vector of error term and the $\beta X+\gamma Z$ term is the linear predictor. We employ a two-level random intercept model with country as the higher level and adolescents as the micro level.

Quantile regressions. Lastly, to assess whether mean peer overweight impacts differently across the distribution of individual weight status (conditional on control variables), we estimate the following quantile regression model at the 25th, 50th and 75th percentiles using the same specifications as in the OLS model:

$$
T_{i}^{q}=\beta_{1}^{q} P_{i}+\beta_{2}^{q} X_{i}+\beta_{3}^{q} M_{i}+\beta_{4}^{q} F+\beta_{5}^{q} C
$$

where $q$ denotes different quantile levels, and $\beta_{1}^{q}$ is the key coefficient of interest. It is worth emphasizing that, relative to mean-based regressions (e.g. OLS estimation), quantile regressions allows the peer effects to differ over the quantiles of individual bodyweight. Thus, quantile regressions allow us to detect whether obese individuals are more vulnerable to their peers. 


\section{Descriptive statistics}

As appendix Table A2 demonstrates, the average $z$-scores of the adolescents' BMI, waist circumference and body fat are $0.688,0.932$ and 0.584 , respectively. The corresponding $z$ scores for their peers are $0.691,0.937$ and 0.567 , respectively. The average age of all the adolescents is approximately 13 years, $45 \%$ of the sample is male, and the adolescents have an average 2.7 designated school friends. It is also worth noting that, on average, they spend about 14 hours a week on leisure time PA versus 24 hours using AVM. The adolescents' mothers have an average BMI of around 25 and $51 \%$ are full-time employed.

\section{Peer effects and adolescent overweight}

OLS and MMGLM estimates. The results for the models with and without controls are reported in Table $2 .{ }^{7}$ Column 1 shows that with only peer overweight controlled for, individual overweight significantly and positively correlates with average peer overweight, although magnitudes vary depending on the measurement used (BMI: 0.258; waist circumference: 0.218; body fat: 0.358 ). These coefficients remain uniformly significant and positive even after columns 2 and 3 introduce individual, mother and household controls and country dummies (Column 2 - OLS with controls: BMI: 0.100; waist circumference: 0.101; body fat: 0.148 and Column 3 - MMGLM: BMI: 0.111; waist circumference: 0.114 ; body fat: 0.158$){ }^{8}$

Table 2

OLS/MMGLM estimates of peer effects on adolescent weight status

\begin{tabular}{lccc}
\hline Variable & OLS & OLS & MMGLM \\
\hline \multicolumn{4}{c}{ BMI (z-score) } \\
\hline Average peer BMI & $(1)$ & $(2)$ & $(3)$ \\
$S E$ & $0.258^{* * *}$ & $0.100^{*}$ & $0.111^{* * * *}$ \\
$95 \% C I$ & $(0.050)$ & $(0.051)$ & $(0.025)$ \\
$N$ & {$[0.160,0.357]$} & {$[0.001,0.200]$} & {$[0.063,0.160]$} \\
$\mathrm{R}^{2}$ & 655 & 655 & 655 \\
\hline \multicolumn{2}{c}{0.291} & \\
\hline Average peer waist circumference & 0.042 & $0.101^{*}$ & $0.114^{* * *}$ \\
$S E$ & $0.218^{* * *}$ & $(0.048)$ & $(0.013)$ \\
$95 \% C I$ & $(0.050)$ & {$[0.007,0.196]$} & {$[0.089,0.139]$}
\end{tabular}

${ }^{7}$ As a robustness check, we also generate a weighted average of the friends' bodyweight through the frequency that each adolescent spends with his/her friends. The results (Table A3 in the Appendix) are quantitatively similar to those in Table 2.

${ }^{8}$ We also introduce peer's averaged mother age, occupational status and BMI in order to control for contextual effects. The results (Table A4 in the Appendix) are quantitatively similar to those in Table 1. A similar strategy has been used in other related studies, for instance, Fortin and Yazbeck (2015) for the U.S and Mora and Gil (2013) for Spain. 


\begin{tabular}{lccc}
$N$ & 646 & 646 & 646 \\
$\mathrm{R}^{2}$ & 0.029 & 0.245 & \\
\hline \multicolumn{4}{c}{ Body fat (z-score) } \\
Average peer body fat & $0.358^{* *}$ & $0.148^{* *}$ & $0.158^{* * *}$ \\
$S E$ & $(0.047)$ & $(0.051)$ & $(0.032)$ \\
$95 \% C I$ & {$[0.265,0.450]$} & {$[0.047,0.249]$} & {$[0.095,0.222]$} \\
$N$ & 646 & 646 & 646 \\
$\mathrm{R}^{2}$ & 0.080 & 0.298 & \\
\hline Controls & No & Yes & Yes \\
\hline
\end{tabular}

Notes: The dependent variables are individual z-scores of BMI, waist circumference (WC) and body fat (BF) based on IOTF criteria. The controls are adolescent characteristics (age, gender, AVM consumption, meal frequency, health-related quality of life, number of friends and time spent together) and mother and family characteristics (age, occupation, BMI and household income). Dependent on regression type, we use country dummies as fixed or random effects. Robust standard errors are in parentheses $(S E) ; 95 \%$ confidence intervals $(C I)$ are in brackets.

${ }^{*} p<0.05$.

${ }^{* *} p<0.01$.

${ }^{* * *} p<0.001$.

Conditional quantile regressions. As Table 3 illustrates, the coefficient of average peer overweight is significantly positive in the median and upper part of the distribution, especially for BMI and body fat. Regarding body fat, the coefficient of average peer overweight at the 75th percentile is stronger than that at the median part of the distribution (50th: $0.146 \mathrm{vs}$. 75 th: 0.167). The results are consistent with those of Trogdon et al. (2008) for the U.S and Nie et al. (2015) for China. With regard to waist circumference, only adolescents at the median distribution show a significant positive association $(50$ th $=0.127)$. This observation of heterogeneous associations produced by different measures of overweight is in line with Burkhauser and Cawley's (2008) finding that different measures of obesity correlate differently with different outcomes of interest. The general impression one gets from Table 3 is that the peer effect is relatively weaker and insignificant in the lower ends of the body weight distributions. Taken at face value, these results would imply that peer weight is more influential among adolescents with higher body weight and they would also provide an explanation for the rise in the right tail of body weight distributions. Policy measures that are aimed at overweight adolescents would thus be particularly effective, i.e., profit the most from the social multiplier effect. However, as pointed out by Trogdon et al. (2008), another possible reason for this observation is that homophily (i.e., selection) might be higher at the upper end of the body distribution than in the lower end.

Table 3

Quantile estimates of peer effects on adolescent weight status

\begin{tabular}{lccc}
\hline Variable & $\mathbf{2 5 \%}$ & $\mathbf{5 0 \%}$ & $\mathbf{7 5 \%}$ \\
\hline & $(1)$ & $(2)$ & $(3)$ \\
\hline & & BMI (z-score) & \\
\hline Average peer BMI & 0.097 & $0.187^{* *}$ & $0.133^{*}$ \\
$S E$ & $(0.060)$ & $(0.060)$ & $(0.067)$
\end{tabular}




\begin{tabular}{|c|c|c|c|}
\hline $95 \% C I$ & {$[-0.022,0.215]$} & {$[0.070,0.305]$} & {$[0.001,0.265]$} \\
\hline $\bar{N}$ & 655 & 655 & 655 \\
\hline Pseudo $R^{2}$ & 0.182 & 0.185 & 0.188 \\
\hline \multicolumn{4}{|c|}{ Waist circumference (z-score) } \\
\hline Average peer WC & 0.109 & $0.127^{*}$ & 0.102 \\
\hline$S E$ & $(0.067)$ & $(0.059)$ & $(0.064)$ \\
\hline $95 \% C I$ & {$[-0.384,0.094]$} & {$[-0.374,0.046]$} & {$[-0.483,-0.028]$} \\
\hline$N$ & 646 & 646 & 646 \\
\hline Pseudo $R^{2}$ & 0.145 & 0.152 & 0.170 \\
\hline \multicolumn{4}{|c|}{ Body fat (z-score) } \\
\hline Average peer BF & 0.115 & $0.146^{*}$ & $0.167^{*}$ \\
\hline$S E$ & $(0.068)$ & $(0.067)$ & $(0.072)$ \\
\hline $95 \% \mathrm{CI}$ & {$[-0.018,0.248]$} & {$[0.015,0.277]$} & {$[0.026,0.309]$} \\
\hline$N$ & 646 & 646 & 646 \\
\hline Pseudo $R^{2}$ & 0.178 & 0.176 & 0.185 \\
\hline
\end{tabular}

Notes: The dependent variables are individual z-scores of BMI, waist circumference (WC) and body fat (BF) based on IOTF criteria. The controls are adolescent characteristics (age, gender, AVM consumption, meal frequency, health-related quality of life, number of friends and time spent together) and mother and family characteristics (age, occupation, BMI and household income). Bootstrapped standard errors are in parentheses $(\mathrm{SE}) ; 95 \%$ confidence intervals $(C I)$ are in brackets.

${ }^{*} p<0.05$.

${ }^{* *} p<0.01$.

${ }^{* * *} p<0.001$.

\section{Mechanisms}

Table 4 reports the results for peer effects on adolescent (un)healthy dietary patterns and PA. Three observations are worth noting: First, in line with prior studies for the U.S. and Netherlands (Bevelander et al., 2012; Salvy et al., 2007a; Salvy et al., 2012; Salvy et al., 2007b), unhealthy food consumption by peers is consistently and positively associated with the adolescents' own unhealthy consumption even after controls are taken into account (Table 4, panel A, columns 1-3). We find no such association, however, between adolescent and peer healthy food consumption. Likewise, although adolescent YHEI in the baseline model is positively and significantly correlated with peer YHEI (panel B, column 1), no such association exists once we take controls into account (Table 4, panel B, columns 2 and 3). Lastly, the results reveal significant positive correlations between the adolescents' leisure time PA and AVM consumption and those of their peers (Table 4, panel C, columns 1-3), which supports the notion that adolescents tend to befriend peers who engage in similar amounts of PA and continue to share similar patterns with their friends (de la Haye et al., 2011b). ${ }^{9}$

\footnotetext{
${ }^{9} \mathrm{We}$ have also estimated the quantile regressions for peer effects on diets, physical activity and sedentary activity. The results indicate that, for sugar consumption, peer influence is stronger at the upper distribution of individual sugar consumption than that at the median (75th: 0.139 vs. 50th: 0.121). In addition, regarding leisure time PA, we find that peer influence is much stronger at the median than that at the 25 th percentile $(0.309$ vs. 0.104$)$. For other unhealthy diets, physical activity and sedentary activity, we cannot observe any heterogeneities among different percentiles. The results are available from the authors upon request.
} 
Table 4

OLS/MMGLM estimates of peer effects on adolescent diets and PA

\begin{tabular}{|c|c|c|c|}
\hline Variables & OLS & OLS & MMGLM \\
\hline & (1) & (2) & (3) \\
\hline \multicolumn{4}{|l|}{ Panel A: Unhealthy diets } \\
\hline \multicolumn{4}{|c|}{ SSB consumption (times per week) } \\
\hline Average peer SSB consumption & $0.197^{* *}$ & $0.157^{*}$ & $0.168^{* *}$ \\
\hline$S E$ & $(0.058)$ & $(.060)$ & $(.059)$ \\
\hline $95 \% C I$ & {$[0.082,0.312]$} & {$[0.038,0.275]$} & {$[0.053,0.282]$} \\
\hline$N$ & 383 & 383 & 383 \\
\hline $\mathrm{R}^{2}$ & 0.026 & 0.105 & \\
\hline \multicolumn{4}{|c|}{ Sugar consumption (times per week) } \\
\hline Average peer sugar consumption & $0.187^{* *}$ & $0.171^{* *}$ & $0.174^{* *}$ \\
\hline$S E$ & $(0.054)$ & $(0.054)$ & $(.053)$ \\
\hline $95 \% C I$ & {$[0.082,0.293]$} & {$[0.065,0.278]$} & {$[0.071,0.277]$} \\
\hline$N$ & 548 & 548 & 548 \\
\hline $\mathrm{R}^{2}$ & 0.022 & 0.077 & \\
\hline \multicolumn{4}{|c|}{ Fatty food consumption (times per week) } \\
\hline Average peer fat consumption & $0.255^{* *}$ & $0.218^{* *}$ & $0.241^{* *}$ \\
\hline$S E$ & $(0.050)$ & $(0.051)$ & $(0.049)$ \\
\hline $95 \% C I$ & {$[0.156,0.353]$} & {$[0.118,0.319]$} & {$[0.144,0.337]$} \\
\hline$N$ & 548 & 548 & 548 \\
\hline $\mathrm{R}^{2}$ & 0.045 & 0.130 & \\
\hline \multicolumn{4}{|c|}{ Fast food consumed as meals } \\
\hline Average peer fast food consumption (meals) & $0.201^{* *}$ & $0.171^{* *}$ & $0.180^{* *}$ \\
\hline$S E$ & $(0.049)$ & $(0.049)$ & $(0.049)$ \\
\hline $95 \% C I$ & {$[0.104,0.298]$} & {$[0.074,0.267]$} & {$[0.084,0.275]$} \\
\hline$N$ & 629 & 629 & 629 \\
\hline $\mathrm{R}^{2}$ & 0.026 & 0.104 & \\
\hline \multicolumn{4}{|l|}{ Panel B: Healthy diets } \\
\hline \multicolumn{4}{|c|}{ Fibre- rich food consumption (times per week) } \\
\hline Average peer fibre consumption & 0.104 & 0.057 & 0.069 \\
\hline$S E$ & $(0.054)$ & $(0.054)$ & $(0.053)$ \\
\hline $95 \% C I$ & {$[-0.002,0.210]$} & {$[-0.050,0.163]$} & {$[-0.035,0.174]$} \\
\hline$N$ & 540 & 540 & 540 \\
\hline $\mathrm{R}^{2}$ & 0.007 & 0.086 & \\
\hline \multicolumn{4}{|c|}{ Vegetable/fruit consumption (times per week) } \\
\hline Average peer vegetable consumption & 0.072 & 0.044 & 0.049 \\
\hline$S E$ & $(0.049)$ & $(0.049)$ & $(0.048)$ \\
\hline $95 \% C I$ & {$[-0.024,0.168]$} & {$[-0.053,0.141]$} & {$[-0.046,0.144]$} \\
\hline$N$ & 589 & 589 & 589 \\
\hline $\mathrm{R}^{2}$ & 0.004 & 0.063 & \\
\hline \multicolumn{4}{|c|}{ YHEI $(0-100)$} \\
\hline Peer YHEI & $0.201^{* *}$ & 0.084 & 0.085 \\
\hline$S E$ & $(0.053)$ & $(0.054)$ & $(0.053)$ \\
\hline $95 \% C I$ & {$[0.097,0.304]$} & {$[-0.022,0.190]$} & {$[-0.020,0.189]$} \\
\hline$N$ & 641 & 641 & 641 \\
\hline $\mathrm{R}^{2}$ & 0.022 & 0.126 & \\
\hline \multicolumn{4}{|l|}{ Panel C: PA and sedentary activity } \\
\hline \multicolumn{4}{|c|}{ Leisure time PA (hours per week) } \\
\hline Average peer PA & $0.283^{* *}$ & $0.262^{* *}$ & $0.272^{* *}$ \\
\hline $\mathrm{SE}$ & $(0.053)$ & $(0.052)$ & $(0.054)$ \\
\hline $95 \% \mathrm{CI}$ & {$[0.178,0.387]$} & {$[0.153,0.371]$} & {$[0.167,0.377]$} \\
\hline$N$ & 466 & 466 & 466 \\
\hline
\end{tabular}




\begin{tabular}{|c|c|c|c|}
\hline $\mathrm{R}^{2}$ & 0.058 & 0.110 & \\
\hline \multicolumn{4}{|c|}{ AVM consumption (hours per week) } \\
\hline Average peer AVM consumption & $0.238^{* *}$ & $0.106^{*}$ & $0.119^{*}$ \\
\hline SE & $(0.045)$ & $(0.048)$ & $(0.046)$ \\
\hline $95 \% \mathrm{CI}$ & {$[0.149,0.327]$} & {$[0.011,0.200]$} & {$[0.028,0.210]$} \\
\hline$N$ & 610 & 610 & 610 \\
\hline $\mathrm{R}^{2}$ & 0.043 & 0.167 & \\
\hline Controls & No & Yes & Yes \\
\hline
\end{tabular}

Notes: The dependent variables are consumption frequency of the various food types (SSBs, simple sugar foods, fatty foods, fast foods consumed as meals/snacks or fibre-rich foods, vegetables/fruits), as well as time spent on PA. Frequencies of fast food consumption as meals or snacks are coded as follows: 1 =never, $2=$ once a month or less, $3=$ several times a month, 4 $=1-2$ times a week and $5=\geq 3$ times a week. The controls are adolescent characteristics (age, gender, meal frequency, healthrelated quality of life, number of friends and time spent together) and mother and family characteristics (age, occupation, BMI, household income). Dependent on regression type, we use country dummies as fixed or random effects. Robust standard errors are in parentheses $(S E) ; 95 \%$ confidence intervals $(C I)$ are in brackets.

${ }^{*} p<0.05$.

${ }^{* *} p<0.01$

${ }^{* * *} p<0.001$.

\section{A note on endogeneity}

Despite wide recognition that inadequate control for peer-group endogeneity, shared environmental influences, and simultaneity can lead to the inflation of peer effects on weight gain (Fletcher, 2011), few studies sufficiently take all these issues into account. In particular, an individual's bodyweight might be correlated with that of a peer group stemming from an endogenous effect, contextual effect, correlated effect, or selection effect. The first denotes a direct influence of the peer group on the individual, whilst the second acknowledges that an individual's bodyweight could be affected by peer group characteristics other than bodyweight (Nie et al., 2015). The third represents that both the individual's and the peers' body weight may be affected by some unobservables (e.g., physical exercise at school), and the fourth recognizes that obese individuals may select friends that are themselves obese. As Trogdon et al. (2008) have emphasized, if a correlation between individual and peer-group obesity emanates from one of the last three effects, then interventions aimed at reducing obesity are less likely to lead to the oft-cited social spill-over effect. Furthermore, not adequately controlling for these effects may result in an overestimation of the peer effect (Fletcher, 2011).

Although the most common way to tackle this issue is by implementing an instrumental variable (IV) approach using the peers' average parental BMI as instruments (Nie et al., 2015; Renna et al., 2008; Trogdon et al., 2008), the validity of doing so is largely dependent on the (critical) assumption that the selection of peers and indirectly of peers' parents is not correlated with an individual's BMI (Trogdon et al., 2008). This assumption, however, is almost certainly false. We know that "friendships could also be selected on the basis of obesity status, with obese youths relatively likely to have obese parents. This strategy may also suffer from a 
second-order case of the reflection problem - friend's parents' weight may be affected by friend's weight which in turn may be affected by the respondent's weight" (Cawley and Ruhm, 2011, p. 136). Perhaps a more promising approach is the Mendelian randomization (MR) approach using genetic variants as instruments, mainly because genes are inherently randomized by a naturally occurring process, assigned at conception, not directly visible and thus unlikely to be related to other individuals (O'Malley et al., 2014; von Hinke et al., 2016). The MR approach is also advantageous because it measures genotypes with higher accuracy, identifies long-term exposure to outcomes of interest, and is immune to biases due to measurement errors (Haycock et al., 2016). Nonetheless, it is also subject to such shortcomings as identification problems related to biological mechanisms, genetic coinheritance and population stratification (von Hinke et al., 2016). In particular, evidence on the biological mechanisms through which the genetic variants may affect individual bodyweight is sparse. It could be that the genetic variants might be associated with other phenotypes and the instruments we use may thus be invalid if those genetic variants affect the outcome of interest directly (von Hinke et al, 2016). Regarding genetic coinheritance (so-called linkage disequilibrium, indicating the association between alleles at different loci within the population), "linkage disequilibrium can exist because alleles are physically close together and tend to be co-inherited, or because they occur together for reasons of population origin in subsections of an overall population and therefore demonstrate a statistical association within the overall population" (Davey Smith and Ebrahim, 2003, p. 5). In such a case, potential violation of the exclusion restriction largely rests on the functions of any co-inherited variants, and on whether those relate to the outcome of interest (von Hinke et al., 2011). Furthermore, the allele frequencies of the single nucleotide polymorphism (SNP) - that explains the largest proportion of the variance - are known to differ by ethnic group (Frayling et al., 2007). The independence assumption might thus be violated when population stratification (due to ethnicity) exists.

Despite these drawbacks, and in order to take advantage of the rich genetic and parental background information provided by the I.Family Study while also acknowledging the inherent endogeneity in our previous models, we combine both these methods in our analysis. Given the evidence that the fat mass and obesity gene (FTO) and the melanocortin-4 receptor gene $(M C 4 R)$ are strongly correlated with overweight and obesity (Lauria et al., 2012; Liu et al., 2013; Speliotes et al., 2010), we follow O’Malley et al. (2014) by employing them as 
instruments. ${ }^{10}$ As in von Hinke et al. (2016), we adopt an additive model to create an unweighted allelic score by summing up the number of obesity-risk alleles carried by each individual to improve the power of the instruments and alleviate weak IV problems. Specifically, the unweighted allelic score is calculated by summing the numbers of the homozygous adiposity-risk genotypes of FTO (rs9939609) $(\mathrm{TT}=0, \mathrm{AT}=1$, and AA = 2) and MC4R (rs17782313) $(\mathrm{TT}=0, \mathrm{CT}=1$, and $\mathrm{CC}=2)$ for each of an adolescent's designated friends. As emphasized by von Hinke et al. (2016), controlling for covariates is particularly important in the presence of population stratification (as in our case) even though the MR approach relies on an unconditional independence assumption. We therefore include the same controls as in the above analysis but employ a two-step generalized method of moments (GMM), which is efficient in the presence of the heteroscedasticity observed here. We also use a limited information maximum likelihood (LIML) estimation, which is generally preferable when instruments are weak.

Using the traditional IV approach, we find no association between adolescent BMI and peer average $\mathrm{BMI}^{11}$ (Table 5, approach 1, panel A) - even though peer parental BMI is significantly and positively associated with peer BMI in the first-stage estimates, regardless of whether the estimates are LIML or GMM (Table 5, approach 1, panel B). Likewise, using MR estimation shows that peer effects vanish when the unweighted allele score is used (Table 5, approach 2, panel B). ${ }^{12}$ For MR estimation, we also perform the weak identification test to assess the validation of our IV. And the results based on the Wald $F$ statistics suggests that our IV suffers from the issue of weak instrument. Therefore, we adopt the LIML instead of 2SLS. At first sight, these results may seem to call into question the very existence of peer effects. Given the substantial drawbacks of both approaches (especially in our setting), however, we believe they warrant no such conclusion. First, an IV approach based on peer background information could be problematic because it comes at the high price of increased measurement error and weaker instruments (Halliday and Kwak, 2009). Second, although the MR method, particularly using unweighted allele scores, might be able to solve the weak instrument and selection bias issues, the above-mentioned identification problems related to biological mechanisms, genetic

\footnotetext{
${ }^{10}$ Put simply, FTO (rs9939609) and MC4R (rs17782313) are used to calculate the unweighted allele score, where the rs-number is an identification tag that uniquely identifies the polymorphism in the genome (von Hinke et al., 2016).

${ }^{11}$ When we apply the same MR strategies to waist circumference and body fat, we generally obtain that results are quantitatively similar to those in Table 4 (available from the author upon request).

${ }^{12}$ As a robustness check, we also use a weighted allele score as the instrument but again obtain similar results to those in Table 4. Following von Hinke et al. (2016), the weights for calculating weighted allele score are defined by the effect size of the obesity-related genetic variants based on an independent meta-analysis (see Speliotes et al., 2010).
} 
coinheritance and population effects remain (von Hinke et al., 2016). Third, and most important in our case, the MR approach requires large sample sizes that encompass both genetic biomarkers and outcomes of interest; otherwise, genetic variants would merely suggest that, as in our case, the peer overweight was not varied enough to affect the adolescents' overweight (von Hinke et al., 2016). It would thus be an over-interpretation of (limited) genetic data to claim that there is no causal relation.

Finally, the same sources of endogeneity also exist for our analyses of PA and diets, yet finding appropriate instruments for these regressions is even harder than in the case of obesity as genetic markers cannot be applied and relevant characteristics of the peers' parents (such as PA of peers' parents) are not available in our data.

Table 5

IV estimates of peer effects on adolescent's BMI

\begin{tabular}{|c|c|c|}
\hline \multicolumn{3}{|l|}{ Approach 1: BMI of peers' parents } \\
\hline \multirow[t]{3}{*}{ Variables } & BMI (z-score) & \\
\hline & LIML & GMM \\
\hline & $(1)$ & $(2)$ \\
\hline \multicolumn{3}{|l|}{ Panel A: First stage IV } \\
\hline Peer's average mothers' BMI & $0.068^{* * *}$ & $0.068^{* * *}$ \\
\hline & $(0.009)$ & $(0.009)$ \\
\hline $95 \% C I$ & {$[0.052,0.085]$} & {$[0.050,0.086]$} \\
\hline Peer's average fathers' BMI & $0.045^{* * *}$ & $0.045^{* * *}$ \\
\hline$S E$ & $(0.010)$ & $(0.011)$ \\
\hline $95 \% C I$ & {$[0.025,0.066]$} & {$[0.023,0.067]$} \\
\hline \multicolumn{3}{|l|}{ Panel B: Second stage IV } \\
\hline Average peer BMI & -0.073 & -0.074 \\
\hline$S E$ & $(0.126)$ & $(0.113)$ \\
\hline $95 \% C I$ & {$[-0.320,0.174]$} & {$[-0.296,0.149]$} \\
\hline$F$-statistic (global) & 9.72 & 16.36 \\
\hline Under-identification test: Kleibergen-Paap rk LM statistic ( $p$-value) & $96.901(0.000)$ & $59.984(0.000)$ \\
\hline Weak identification test: Wald $F$-statistic & $55.211(>10 \%)$ & $45.900(>10 \%)$ \\
\hline Over-identification test: Hansen $J$ statistic ( $p$-value) & $0.164(0.686)$ & $0.168(0.682)$ \\
\hline Controls & Yes & Yes \\
\hline Country dummies & Yes & Yes \\
\hline$N$ & 605 & 605 \\
\hline$R^{2}$ & 0.279 & 0.279 \\
\hline \multicolumn{3}{|l|}{ Approach 2: Mendelian Randomization } \\
\hline \multirow[t]{2}{*}{ Variables } & BMI (z-score) & \\
\hline & LIML & \\
\hline \multicolumn{3}{|l|}{ Panel A: First stage IV } \\
\hline Unweighted allele score & 0.052 & \\
\hline$S E$ & $(0.042)$ & \\
\hline $95 \% C I$ & {$[-0.030,0.134]$} & \\
\hline \multicolumn{3}{|l|}{ Panel B: Second stage IV } \\
\hline Average peer BMI & 0.761 & \\
\hline$S E$ & $(1.422)$ & \\
\hline $95 \% C I$ & {$[-2.037,3.558]$} & \\
\hline First stage F-statistic & 1.56 & \\
\hline Weak identification test: Wald $F$-statistic & $1.559(<10 \%)$ & \\
\hline Country dummies & Yes & \\
\hline Controls & Yes & \\
\hline$N$ & 335 & \\
\hline
\end{tabular}

Notes: The dependent variable is individual $z$-score of BMI based on 2012 IOTF criteria. The controls for the models in 
scenarios 1 and 2 are adolescent characteristics (age, gender, AVM consumption, meal frequency, health-related quality of life, number of friends and time spent together) and mother and family characteristics (age, occupation, BMI and household income). The instruments for the models in scenario 1 are peers' parental average BMI. The instrument for the model in scenario 2 is individual unweighted allele score. Robust standard errors are in parentheses $(S E)$.

$* p<0.05$.

$* * p<0.01$.

$* * * p<0.001$.

\section{DISCUSSION AND CONCLUSIONS}

To remedy the dearth of European empirical research on whether - and through which mechanisms - peer weight status and behaviour patterns might affect adolescent body fat (Salvy et al., 2012), this analysis uses I.Family Study data to probe for such effects on three different measures of overweight (BMI, waist circumference and body fat). Our results, derived for a sample of adolescents aged 12-16 from six European countries, provide evidence of peer effects irrespective of the measure of overweight, although the estimates for each of these do differ in magnitude. We also find that these effects are stronger among individuals at the upper end of the body fat distribution. This is a common finding in the literature (see, for instance, Trodgon et al., 2008; Halliday and Kwak, 2009; Loh and Li, 2013; Nie et al., 2015) and may aside from capturing a peer effect - also suggest that adolescents with higher weight status are subject to greater stigmatisation and exclusion, and therefore tend to adopt similar behaviours (e.g. not being active outdoors or staying indoors at the computer/TV). However, as Trodgon et al. (2008) have highlighted, the results may also reflect selection being higher at the right end of the overweight distribution.

Turning our attention to possible pathways through which peers might influence adolescent overweight, we find evidence that both the adolescents' consumption of less healthy foods (SSBs, simple sugar, fatty foods, and fast foods as meals) and their YHEI are positively correlated with those of their peers. The elasticities ${ }^{13}$ of peer effects in SSBs, simple sugar, fatty foods and fast foods as meals are $0.180,0.173,0.230$ and 0.187 , respectively. In the case of fast foods, this would imply that, on average, an individual's fast food consumption would increase by $0.187 \%$ in response to a $1 \%$ increase in the peers' fast food consumption. These results are well in line with the elasticities for fast food in Fortin and Yazbeck (2015) and Ali et al. (2011b) for the U.S (0.208 and 0.178, respectively). We find no such association, however, for the consumption of healthy foods (e.g., vegetables, fruits and other fibre-rich foods). This observation is similar to that of Ali et al. (2011b) for the U.S., who also find no evidence of peer effects on fruits and vegetables. A positive association also exists between the time adolescents spend on leisure time PA and AVM and the time spent by their friends on

${ }^{13}$ We calculate the elasticities at the sample means. 
similar activities, with elasticities of 0.268 and 0.108 , respectively (in Ali et al., 2011b, in the elasticities for pursuing an active sport and regular exercise are 0.079 and 0.184 , respectively). These findings suggest that peer effects on adolescent overweight could operate through friends' behaviour patterns, particularly unhealthy food consumption, physical activity and sedentary behaviours.

The strength of our analysis lies in its rich set of body composition/weight status data, which considerably extends the limited research evidence available for (continental) Europe, the range of behavioural measures included representing diet, physical activity and sedentary behaviours and the approach to analysis to accommodate endogeneity effects. Its main limitation is its cross-sectional design and relatively small sample size, which makes a causal analysis difficult. Hence, although we attempt to identify causality by applying an IV approach (using peers' parental BMI and genetic variants), identification problems remain, and our results must be treated as associations. Our cross sectional data also make it impossible to explore the dynamic relationship between peer effects and individual bodyweight over time. Moreover, regarding physical activity, we only employ a partial measure of physical activity (unstructured activity in leisure time) which may not reflect school-based peer relations or those that take place indoors (e.g. structured sport activities), although it could be argued that unstructured leisure time physical activity is most likely to be influenced by peer groups.

Keeping in mind these methodological shortcomings, our finding that mainly unhealthy dietary patterns and PA are positively correlated between adolescents and their peers could be used in interventions targeting the peers in addition to the individual adolescent or by addressing the composition of peer groups (O'Malley et al., 2014). Like some other studies (Dishion and Tipsord, 2010; Prinstein and Dodge, 2008), our findings indicate the existence of a "social multiplier effect" - not only for obesity, but also for unhealthy dietary patterns as well as physical activity and sedentary time. Such a multiplier effect has been largely attributed to in-group social norms, i.e., perceptions that prescribe or influence behaviour (Schultz et al., 2007). By also addressing peers, even small changes by some group members seem to be able to shift group norms on dietary behaviour or PA (Graham, 2008). Yet, what has been known and used in social norms interventions for smoking (Mercken et al., 2012), drinking (Balsa et al., 2011), promiscuous behaviour and other problematic teen behaviour (McAlaney et al., 2010) since decades, has only come to the attention of adolescent obesity research or policymakers recently. It becomes clear that when designing effective public health policies and social marketing campaigns, peer influence and social networks should be taken into account. 
Failure to do so may underestimate the cost-effectiveness of obesity prevention and intervention programs.

\section{REFEREMCES}

Ahrens, W., Pigeot, I., Pohlabeln, H., De Henauw, S., Lissner, L., Molnar, D., Moreno, L. A., Tornaritis, M., Veidebaum, T. and Siani, A. (2014). Prevalence of overweight and obesity in European children below the age of 10. International Journal of Obesity, 38: S99-S107.

Ahrens, W., Siani, A., Adan, R., De Henauw, S., Eiben, G., Gwozdz, W., Hebestreit, A., Hunsberger, M., Kaprio, J., Krogh, V., Lissner, L., Molnár, D., Moreno, L. A., Page, A., Picó, C., Reisch, L., Smith, R. M., Tornaritis, M., Veidebaum, T., Williams, G., Pohlabeln, H., Pigeot, I. and on behalf of the, I. Family consortium (2017). Cohort Profile: The transition from childhood to adolescence in European children-how I.Family extends the IDEFICS cohort. International Journal of Epidemiology, 46: 1394-1395j.

Ali, Mir M., Amialchuk, Aliaksandr and Heiland, Frank W. (2011a). Weight-related behavior among adolescents: The role of peer effects. PLOS ONE, 6: e21179.

Ali, Mir M., Amialchuk, Aliaksandr and Renna, Francesco (2011b). Social network and weight misperception among adolescents. Southern Economic Journal, 77: 827-842.

Arvidsson, L., Bogl, L. H., Eiben, G., Hebestreit, A., Nagy, P., Tornaritis, M., Moreno, L. A., Siani, A., Veidebaum, T., De Henauw, S., Lissner, L., on behalf of the, Idefics and consortia, I. Family (2015). Fat, sugar and water intakes among families from the IDEFICS intervention and control groups: first observations from I.Family. Obesity Reviews, 16: 127-137.

Asirvatham, Jebaraj, Nayga, Rodolfo M. and Thomsen, Michael R. (2014). Peer-effects in obesity among public elementary school children: A grade-level analysis. Applied Economic Perspectives and Policy, 36: 438-459.

Balsa, Ana I., Homer, Jenny F. , French, Michael T. and Norton, Edward C. (2011). Alcohol use and popularity: Social payoffs from conforming to peers' behavior. Journal of Research on Adolescence, 21:559-568.

Bammann, K., Huybrechts, I., Vicente-Rodriguez, G., Easton, C., De Vriendt, T., Marild, S., Mesana, M. I., Peeters, M. W., Reilly, J. J., Sioen, I., Tubic, B., Wawro, N., Wells, J. C., Westerterp, K., Pitsiladis, Y. and Moreno, L. A. (2013). Validation of anthropometry and foot-to-foot bioelectrical resistance against a threecomponent model to assess total body fat in children: the IDEFICS study. International Journal of Obesity, 37: 520-526.

Barlow, Sarah E. (2007). Expert committee recommendations regarding the prevention, assessment, and treatment of child and adolescent overweight and obesity: Summary report. Pediatrics, 120: S164-S192.

Bel-Serrat, S., Mouratidou, T., Börnhorst, C., Peplies, J., De Henauw, S., Marild, S., Molnár, D., Siani, A., Tornaritis, M., Veidebaum, T., Krogh, V. and Moreno, L. A. (2013). Food consumption and cardiovascular risk factors in European children: the IDEFICS study. Pediatric Obesity, 8: 225-236.

Bevelander, Kirsten E., Anschütz, Doeschka J. and Engels, Rutger C. M. E. (2012). Social norms in food intake among normal weight and overweight children. Appetite, 58: 864-872.

Blanchflower, David G., van Landeghem, Bert and Oswald, Andrew J. (2009). Imitative obesity and relative utility Journal of the European Economic Association, 7: 528-538.

Bullinger, Monika, Brütt, Levke Anna, Erhart, Michael and Ravens-Sieberer, Ulrike (2008). Psychometric properties of the KINDL-R questionnaire: results of the BELLA study. European Child \& Adolescent Psychiatry, 17: 125-132.

Burkhauser, Richard V. and Cawley, John (2008). Beyond BMI: The value of more accurate measures of fatness and obesity in social science research. Journal of Health Economics, 27: 519-529.

Cawley, John and Ruhm, Christopher J. (2011). Chapter Three - The Economics of Risky Health Behaviors. in: Thomas G. Mcguire Mark V. Pauly and P. Barros Pedro (eds.) Handbook of Health Economics. Elsevier.

Christakis, Nicholas A. and Fowler, James H. (2007). The spread of obesity in a large social network over 32 years. New England Journal of Medicine, 357: 370-379.

Cohen-Cole, Ethan and Fletcher, Jason M. (2008). Is obesity contagious? Social networks vs. environmental factors in the obesity epidemic. Journal of Health Economics, 27: 1382-1387.

Cole, Tim J., Bellizzi, Mary C., Flegal, Katherine M. and Dietz, William H. (2000). Establishing a standard definition for child overweight and obesity worldwide: International survey. BMJ, 320: 1240.

Davey Smith, George and Ebrahim, Shah (2003). 'Mendelian randomization': Can genetic epidemiology contribute to understanding environmental determinants of disease?*. International Journal of Epidemiology, 32: $1-22$.

de la Haye, Kayla, Robins, Garry, Mohr, Philip and Wilson, Carlene (2011a). Homophily and contagion as explanations for weight similarities among adolescent friends. Journal of Adolescent Health, 49: 421-427.

de la Haye, Kayla, Robins, Garry, Mohr, Philip and Wilson, Carlene (2011b). How physical activity shapes, and is shaped by, adolescent friendships. Social Science \& Medicine, 73: 719-728. 
Dishion, Thomas J. and Tipsord, Jessica M. (2010). Peer contagion in child and adolescent social and emotional development. Annual Review of Psychology, 62: 189-214.

European Commission (2013). New study to provide insights into young Europeans' health-related diet and lifestyle choices. Brussels: European Commission.

European Commission (2014). EU action plan on childhood obesity 2014-2020. Brussels: European Commission

Feskanich, Diane, Rockett, Helaine R. H. and Colditz, Graham A. (2004). Modifying the healthy eating index to assess diet quality in children and adolescents. Journal of the American Dietetic Association, 104: 1375-1383.

Fletcher, Iason M. (2011). Peer effects and obesity. in: J. Cawley (ed.) The Oxford Handbook of the Social Science of Obesity. Oxford: Oxford University Press.

Fortin, Bernard and Yazbeck, Myra (2015). Peer effects, fast food consumption and adolescent weight gain. Journal of Health Economics, 42: 125-138.

Fowler, J. H. and Christakis, N. A. (2008). Estimating peer effects on health in social networks: A response to Cohen-Cole and Fletcher; and Trogdon, Nonnemaker, and Pais. Journal of Health Economics, 27: 1400-1405.

Frayling, Timothy M., Timpson, Nicholas J., Weedon, Michael N., Zeggini, Eleftheria, Freathy, Rachel M., Lindgren, Cecilia M., Perry, John R. B., Elliott, Katherine S., Lango, Hana, Rayner, Nigel W., Shields, Beverley, Harries, Lorna W., Barrett, Jeffrey C., Ellard, Sian, Groves, Christopher J., Knight, Bridget, Patch, Ann-Marie, Ness, Andrew R., Ebrahim, Shah, Lawlor, Debbie A., Ring, Susan M., Ben-Shlomo, Yoav, Jarvelin, Marjo-Riitta, Sovio, Ulla, Bennett, Amanda J., Melzer, David, Ferrucci, Luigi, Loos, Ruth J. F., Barroso, Inês, Wareham, Nicholas J., Karpe, Fredrik, Owen, Katharine R., Cardon, Lon R., Walker, Mark, Hitman, Graham A., Palmer, Colin N. A., Doney, Alex S. F., Morris, Andrew D., Smith, George Davey, Hattersley, Andrew T. and McCarthy, Mark I. (2007). A common variant in the FTO gene is associated with body mass index and predisposes to childhood and adult obesity. Science, 316: 889-894.

Gallagher, Dympna, Visser, Marjolein, Sepúlveda, Dennis, Pierson, Richard N., Harris, Tamara and Heymsfield, Steven B. (1996). How useful is body mass index for comparison of body fatness across age, sex, and ethnic groups? American Journal of Epidemiology, 143: 228-239.

Graham, Carol (2008). Happiness and health: Lessons - and questions - for public policy. Health Affairs, 27: 7287.

Gwozdz, Wencke, Sousa-Poza, Alfonso, Reisch, Lucia A., Ahrens, Wolfgang, Eiben, Gabriele, M. FernandézAlvira, Juan, Hadjigeorgiou, Charalampos, De Henauw, Stefaan, Kovács, Eva, Lauria, Fabio, Veidebaum, Toomas, Williams, Garrath and Bammann, Karin (2013). Maternal employment and childhood obesity - A European perspective. Journal of Health Economics, 32: 728-742.

Gwozdz, Wencke, Sousa-Poza, Alfonso, Reisch, Lucia A., Bammann, Karin, Eiben, Gabriele, Kourides, Yiannis, Kovács, Éva, Lauria, Fabio, Konstabel, Kenn, Santaliestra-Pasias, Alba M., Vyncke, Krishna and Pigeot, Iris (2015). Peer effects on obesity in a sample of European children. Economics \& Human Biology, 18: 139-152.

Halliday, Timothy J. and Kwak, Sally (2009). Weight gain in adolescents and their peers. Economics \& Human Biology, 7: 181-190.

Haycock, Philip C., Burgess, Stephen, Wade, Kaitlin H., Bowden, Jack, Relton, Caroline and Davey Smith, George (2016). Best (but oft-forgotten) practices: The design, analysis, and interpretation of Mendelian randomization studies. The American Journal of Clinical Nutrition, 103: 965-978.

Hill, James O. and Peters, John C. (1998). Environmental contributions to the obesity epidemic. Science, 280: 1371-1374.

Huybrechts, I., Bornhorst, C., Pala, V., Moreno, L. A., Barba, G., Lissner, L., Fraterman, A., Veidebaum, T., Hebestreit, A., Sieri, S., Ottevaere, C., Tornaritis, M., Molnar, D., Ahrens, W. and De Henauw, S. (2011). Evaluation of the Children's Eating Habits Questionnaire used in the IDEFICS study by relating urinary calcium and potassium to milk consumption frequencies among European children. International Journal of Obesity, 35: S69-S78.

Huybrechts, Inge, De Bacquer, Dirk, Van Trimpont, Inge, De Backer, Guy and De Henauw, Stefaan (2006). Validity of parentally reported weight and height for preschool-aged children in Belgium and its impact on classification into body mass index categories. Pediatrics, 118: 2109-2118.

Konnopka, A., Bödemann, M. and König, H. H. (2011). Health burden and costs of obesity and overweight in Germany. The European Journal of Health Economics, 12: 345-352.

Lanfer, A., Hebestreit, A., Ahrens, W., Krogh, V., Sieri, S., Lissner, L., Eiben, G., Siani, A., Huybrechts, I., Loit, H. M., Papoutsou, S., Kovacs, E. and Pala, V. (2011). Reproducibility of food consumption frequencies derived from the Children's Eating Habits Questionnaire used in the IDEFICS study. International Journal of Obesity, 35: S61-S68.

Larson, N. I., Wall, M. M., Story, M. T. and Neumark-Sztainer, D. R. (2013). Home/family, peer, school, and neighborhood correlates of obesity in adolescents. Obesity, 21: 1858-1869.

Lauria, Fabio, Siani, Alfonso, Bammann, Karin, Foraita, Ronja, Huybrechts, Inge, Iacoviello, Licia, Koni, Anna C., Kourides, Yannis, Marild, Staffan, Molnar, Denes, Moreno, Luis A., Pigeot, Iris, Pitsiladis, Yannis P., Veidebaum, Toomas, Russo, Paola and Consortium, Idefics (2012). Prospective analysis of the association of a common variant of FTO (rs9939609) with adiposity in children: Results of the IDEFICS study. PLoS ONE, 7: e48876. 
Leatherdale, Scott T. and Papadakis, Sophia (2009). A multi-level examination of the association between older social models in the school environment and overweight and obesity among younger students. Journal of Youth and Adolescence, 40: 361-372.

Lehnert, Thomas, Streltchenia, Pawel, Konnopka, Alexander, Riedel-Heller, Steffi G. and König, Hans-Helmut (2015). Health burden and costs of obesity and overweight in Germany: An update. The European Journal of Health Economics, 16: 957-967.

Liu, Chibo, Mou, Sihua and Cai, Yangqun (2013). FTO gene variant and risk of overweight and obesity among children and adolescents: A systematic review and meta-analysis. PLoS ONE, 8: e82133.

Loh, Chung-Ping A. and Li, Qiang (2013). Peer effects in adolescent bodyweight: Evidence from rural China. Social Science \& Medicine, 86: 35-44.

Maximova, K., McGrath, J. J., Barnett, T., O'Loughlin, J., Paradis, G. and Lambert, M. (2008). Do you see what I see? Weight status misperception and exposure to obesity among children and adolescents. International Journal of Obesity, 32: 1008-1015.

McAlaney, J., Bewick, B. M. and Bauerle, J. (2010). Social norms guidebook: A guide to implementing the social norms approach in the UK, West Yorkshire, UK: University of Bradford, University of Leeds, Department of Health.

McCarthy, H. D., Cole, T. J., Fry, T., Jebb, S. A. and Prentice, A. M. (2006). Body fat reference curves for children. International Journal of Obesity, 30: 598-602.

Mercken, L., Steglich, C., Sinclair, P., Holliday, J. and Moore, L. (2012). A longitudinal social network analysis of peer influence, peer selection, and smoking behavior among adolescents in British schools. Health Psychology, 31: 450-459.

Mora, Toni and Gil, Joan (2013). Peer effects in adolescent BMI: Evidence from Spain Health Economics, 22: 501-516.

Nie, Peng, Sousa-Poza, Alfonso and He, Xiaobo (2015). Peer effects on childhood and adolescent obesity in China. China Economic Review, 35: 47-69.

O'Malley, A. James, Elwert, Felix, Rosenquist, J. Niels, Zaslavsky, Alan M. and Christakis, Nicholas A. (2014). Estimating peer effects in longitudinal dyadic data using instrumental variables. Biometrics, 70: 506-515.

OECD (2012). OECD obesity update 2012. Paris: OECD.

Prinstein, M.J. and Dodge, K.A. (2008). Understanding peer influence in children and adolescents, New York: The Guilford Press.

Quinto Romani, Annette (2014). Estimating the peer effect on youth overweight and inactivity using an intervention study. Journal of School Health, 84: 617-624.

Ravens-Sieberer, Ulrike, Gosch, Angela, Rajmil, Luis, Erhart, Michael, Bruil, Jeanet, Power, Mick, Duer, Wolfgang, Auquier, Pascal, Cloetta, Bernhard, Czemy, Ladislav, Mazur, Joanna, Czimbalmos, Agnes, Tountas, Yannis, Hagquist, Curt and Kilroe, Jean (2008). The KIDSCREEN-52 quality of life measure for children and adolescents: Psychometric results from a cross-cultural survey in 13 European countries. Value in Health, 11: 645-658.

Renna, Francesco, Grafova, Irina B. and Thakur, Nidhi (2008). The effect of friends on adolescent body weight. Economics \& Human Biology, 6: 377-387.

Romero-Corral, Abel, Montori, Victor M., Somers, Virend K., Korinek, Josef, Thomas, Randal J., Allison, Thomas G., Mookadam, Farouk and Lopez-Jimenez, Francisco (2006). Association of bodyweight with total mortality and with cardiovascular events in coronary artery disease: a systematic review of cohort studies. The Lancet, 368: 666-678.

Salvy, Sarah-Jeanne, Coelho, Jennifer S., Kieffer, Elizabeth and Epstein, Leonard H. (2007a). Effects of social contexts on overweight and normal-weight children's food intake. Physiology \& Behavior, 92: 840-846.

Salvy, Sarah-Jeanne, de la Haye, Kayla, Bowker, Julie C. and Hermans, Roel C. J. (2012). Influence of peers and friends on children's and adolescents' eating and activity behaviors. Physiology \& Behavior, 106: 369-378.

Salvy, Sarah-Jeanne, Romero, Natalie, Paluch, Rocco and Epstein, Leonard H. (2007b). Peer influence on preadolescent girls' snack intake: Effects of weight status. Appetite, 49: 177-182.

Schultz, P. Wesley, Nolan, Jessica M., Cialdini, Robert B., Goldstein, Noah J. and Griskevicius, Vladas (2007). The constructive, destructive, and reconstructive power of social norms. Psychological Science, 18: 429-434.

Shields, M. , Connor, G.S., Janssen, I. and Tremblay, M.S. (2011). Obesity estimates for children based on parentreported versus direct measures. Health Reports, 22: 47-58.

Speliotes, Elizabeth K., Willer, Cristen J., Berndt, Sonja I., Monda, Keri L., Thorleifsson, Gudmar, Jackson, Anne U., Allen, Hana Lango, Lindgren, Cecilia M., Luan, Jian'an, Magi, Reedik, Randall, Joshua C., Vedantam, Sailaja, Winkler, Thomas W., Qi, Lu, Workalemahu, Tsegaselassie, Heid, Iris M., Steinthorsdottir, Valgerdur, Stringham, Heather M., Weedon, Michael N., Wheeler, Eleanor, Wood, Andrew R., Ferreira, Teresa, Weyant, Robert J., Segre, Ayellet V., Estrada, Karol, Liang, Liming, Nemesh, James, Park, Ju-Hyun, Gustafsson, Stefan, Kilpelainen, Tuomas O., Yang, Jian, Bouatia-Naji, Nabila, Esko, Tonu, Feitosa, Mary F., Kutalik, Zoltan, Mangino, Massimo, Raychaudhuri, Soumya, Scherag, Andre, Smith, Albert Vernon, Welch, Ryan, Zhao, Jing Hua, Aben, Katja K., Absher, Devin M., Amin, Najaf, Dixon, Anna L., Fisher, Eva, Glazer, Nicole L., Goddard, Michael E., Heard-Costa, Nancy L., Hoesel, Volker, Hottenga, Jouke-Jan, Johansson, Asa, Johnson, Toby, Ketkar, Shamika, Lamina, Claudia, Li, Shengxu, Moffatt, Miriam F., Myers, Richard H., 
Narisu, Narisu, Perry, John R. B., Peters, Marjolein J., Preuss, Michael, Ripatti, Samuli, Rivadeneira, Fernando, Sandholt, Camilla, Scott, Laura J., Timpson, Nicholas J., Tyrer, Jonathan P., van Wingerden, Sophie, Watanabe, Richard M., White, Charles C., Wiklund, Fredrik, Barlassina, Christina, Chasman, Daniel I., Cooper, Matthew N., Jansson, John-Olov, Lawrence, Robert W., Pellikka, Niina, Prokopenko, Inga, Shi, Jianxin, Thiering, Elisabeth, Alavere, Helene, Alibrandi, Maria T. S., Almgren, Peter, Arnold, Alice M., Aspelund, Thor, Atwood, Larry D., Balkau, Beverley, Balmforth, Anthony J., Bennett, Amanda J., BenShlomo, Yoav, Bergman, Richard N., Bergmann, Sven, Biebermann, Heike, Blakemore, Alexandra I. F., Boes, Tanja, Bonnycastle, Lori L., Bornstein, Stefan R., Brown, Morris J., Buchanan, Thomas A., et al. (2010). Association analyses of 249,796 individuals reveal 18 new loci associated with body mass index. Nature Genetics, 42: 937-948.

The World Health Organization Regional Office for Europe (2010). European Childhood Obesity Surveillance Initiative, COSI, round 2010. Copenhagen: The World Health Organization Regional Office for Europe.

Tremmel, M., Gerdtham, U.-G., Nilsson, P.M. and Saha, S. (2017). Economic burden of obesity: A systematic literature review. International Journal of Environmental Research and Public Health, 14: 435.

Trogdon, Justin G., Nonnemaker, James and Pais, Joanne (2008). Peer effects in adolescent overweight. Journal of Health Economics, 27: 1388-1399.

Valente, Thomas W., Fujimoto, Kayo, Chou, Chih-Ping and Spruijt-Metz, Donna (2009). Adolescent affiliations and adiposity: A social network analysis of friendships and obesity. Journal of Adolescent Health, 45: 202204.

von Hinke, Stephanie, Davey Smith, George, Lawlor, Debbie A., Propper, Carol and Windmeijer, Frank (2016). Genetic markers as instrumental variables. Journal of Health Economics, 45: 131-148.

von Hinke, Stephanie, Smith, George Davey, Lawlor, Debbie A., Propper, Carol and Windmeijer, Frank (2011). Mendelian randomization: The use of genes in instrumental variable analyses. Health Economics, 20: 893896.

Wellens, Rita I., Roche, Alex F., Khamis, Harry J., Jackson, Andrew S., Pollock, Michael L. and Siervogel, Roger M. (1996). Relationships between the body mass index and body composition. Obesity Research, 4: 35-44.

Yakusheva, Olga, Kapinos, Kandice A. and Eisenberg, Daniel (2014). Estimating heterogeneous and hierarchical peer effects on body weight using roommate assignments as a natural experiment. Journal of Human Resources, 49: 234-261.

Yakusheva, Olga, Kapinos, Kandice and Weiss, Marianne (2011). Peer effects and the freshman 15: Evidence from a natural experiment. Economics \& Human Biology, 9: 119-132.

Yang, Muzhe and Huang, Rui (2013). Asymmetric association between exposure to obesity and weight gain among adolescents. Eastern Economic Journal, 40: 96-118.

Yusuf, Salim, Hawken, Steven, Ônpuu, Stephanie, Bautista, Leonelo, Franzosi, Maria Grazia, Commerford, Patrick, Lang, Chim C., Rumboldt, Zvonko, Onen, Churchill L., Lisheng, Liu, Tanomsup, Supachai, Wangai, Paul, Jr., Razak, Fahad, Sharma, Arya M. and Anand, Sonia S. (2005). Obesity and the risk of myocardial infarction in 27,000 participants from 52 countries: A case-control study. The Lancet, 366: 1640-1649. 


\section{APPENDIX}

Table A1.

Survey item on peer networks in the I.Family Study

Please tell us the first, last names and the class of up to 10 people who are your friends.

Tick the number (1-5) that shows how "much time" you spend with your friends.

1 "a lot time" means

that you are often together.

name/

if same

school,

Friend's I.Family Friend's IDEFICS friend's time

ID Number

ID Number

class

(1)

(2)

(3)

Some

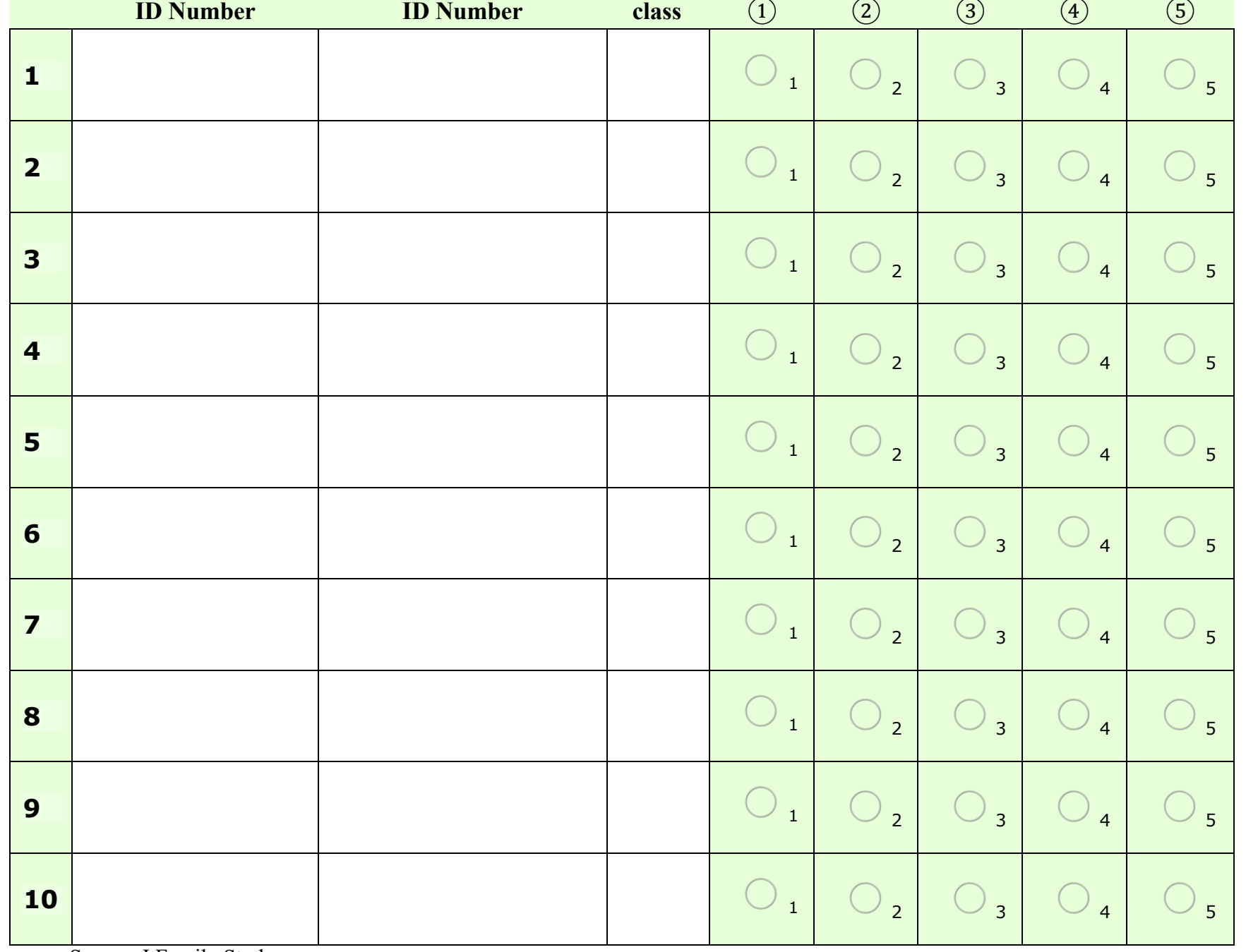

Source: I.Family Study. 
Table A2.

Descriptive statistics

\begin{tabular}{|c|c|c|c|}
\hline Variables & Obs & Mean & Std. Dev. \\
\hline \multicolumn{4}{|l|}{ Adolescent weight status } \\
\hline BMI $z$-score & 655 & 0.688 & 1.096 \\
\hline Waist circumference $z$-score & 653 & 0.932 & 1.216 \\
\hline Body fat $z$-score & 652 & 0.584 & 1.057 \\
\hline \multicolumn{4}{|l|}{ Peer weight status } \\
\hline BMI $z$-score & 655 & 0.691 & 0.868 \\
\hline Waist circumference $z$-score & 648 & 0.937 & 0.957 \\
\hline Body fat $z$-score & 649 & 0.567 & 0.831 \\
\hline \multicolumn{4}{|l|}{ Adolescent diets } \\
\hline Sugar sweetened beverages (SSBs, times a day) & 393 & 0.828 & 0.959 \\
\hline Simple sugar foods (times a day) & 572 & 3.495 & 2.300 \\
\hline Fatty foods (times a day) & 564 & 1.320 & 1.302 \\
\hline Vegetables/fruits (times a day) & 609 & 3.237 & 2.569 \\
\hline Fibre-rich foods (times a day) & 574 & 4.413 & 3.308 \\
\hline Youth Healthy Eating Index (YHEI, 0-100) & 644 & 49.79 & 9.063 \\
\hline Fast foods consumed as meals $(1-5)$ & 642 & 3.944 & 0.909 \\
\hline \multicolumn{4}{|l|}{ Adolescent PA } \\
\hline Time spent on PA (hours per week) & 500 & 14.177 & 9.382 \\
\hline \multicolumn{4}{|l|}{ Information on peers } \\
\hline Time spent together $(1-5,1=\mathrm{a}$ lot of time to $5=$ some time $)$ & 655 & 2.333 & 0.997 \\
\hline Number of friends & 655 & 2.664 & 1.671 \\
\hline \multicolumn{4}{|l|}{ Adolescent characteristics } \\
\hline $\operatorname{Sex}(1=$ male, $0=$ female $)$ & 655 & 0.452 & 0.498 \\
\hline Age & 655 & 13.419 & 0.654 \\
\hline AVM consumption (hours per week) & 655 & 23.823 & 11.664 \\
\hline Meal frequency (times a day) & 655 & 3.941 & 0.992 \\
\hline Health-related quality of life $(0-64)$ & 655 & 37.866 & 5.780 \\
\hline \multicolumn{4}{|l|}{ Mother and family characteristics } \\
\hline Mother's age & 655 & 42.220 & 5.093 \\
\hline Mother’s BMI (kg/m²) & 655 & 25.354 & 5.236 \\
\hline \multicolumn{4}{|l|}{ Mother's occupation } \\
\hline Not employed & 655 & 0.244 & 0.430 \\
\hline Full time & 655 & 0.508 & 0.500 \\
\hline Part time $\geq 15$ hours & 655 & 0.148 & 0.355 \\
\hline Part time $<15$ hours & 655 & 0.064 & 0.245 \\
\hline On leave & 655 & 0.029 & 0.168 \\
\hline In education & 655 & 0.006 & 0.078 \\
\hline \multicolumn{4}{|l|}{ Household income categories } \\
\hline Low level & 655 & 0.278 & 0.448 \\
\hline Low-medium level & 655 & 0.096 & 0.295 \\
\hline Medium level & 655 & 0.287 & 0.453 \\
\hline Medium-high level & 655 & 0.093 & 0.291 \\
\hline High level & 655 & 0.246 & 0.431 \\
\hline
\end{tabular}

Source: I.Family Study.

Notes: The frequencies of fast foods consumed as meals or snacks are both scaled on a 5 -point $(1=$ never, $2=$ once a month or less, $3=$ several times a month, $4=1-2$ times a week and $5=\geq 3$ times a week). Time spent on PA (hours per week) is the sum of time spent playing/hanging out outdoors on weekdays after school and weekends, respectively. 
Table A3

OLS/MMGLM estimates of peer effects on adolescent weight status (using weighted peer measure)

\begin{tabular}{|c|c|c|c|}
\hline Variable & OLS & OLS & MMGLM \\
\hline & (1) & (2) & (3) \\
\hline \multicolumn{4}{|c|}{ BMI (z-score) } \\
\hline Average peer BMI & $0.154^{* * *}$ & 0.057 & $0.064^{*}$ \\
\hline$S E$ & $(0.036)$ & $(0.036)$ & $(0.033)$ \\
\hline $95 \% C I$ & {$[0.083,0.225]$} & {$[-0.014,0.127]$} & {$[0.0002,0.128]$} \\
\hline$N$ & 655 & 655 & 655 \\
\hline $\mathrm{R}^{2}$ & 0.026 & 0.287 & \\
\hline \multicolumn{4}{|c|}{ Waist circumference (z-score) } \\
\hline Average peer waist circumference & $0.138^{* * *}$ & $0.069^{*}$ & $0.077^{* * *}$ \\
\hline$S E$ & $(0.034)$ & $(0.034)$ & $(0.023)$ \\
\hline $95 \% C I$ & {$[0.071,0.206]$} & {$[0.003,0.135]$} & {$[0.032,0.122]$} \\
\hline$N$ & 646 & 646 & 646 \\
\hline $\mathrm{R}^{2}$ & 0.023 & 0.245 & \\
\hline \multicolumn{4}{|c|}{ Body fat (z-score) } \\
\hline Average peer body fat & $0.228^{* *}$ & $0.093^{* *}$ & $0.099^{* * *}$ \\
\hline$S E$ & $(0.037)$ & $(0.038)$ & $(0.033)$ \\
\hline $95 \% C I$ & {$[0.156,0.300]$} & {$[0.017,0.168]$} & {$[0.035,0.163]$} \\
\hline$N$ & 646 & 646 & 646 \\
\hline $\mathrm{R}^{2}$ & 0.056 & 0.295 & \\
\hline Controls & No & Yes & Yes \\
\hline
\end{tabular}

Notes: The dependent variables are individual z-scores of BMI, waist circumference (WC) and body fat (BF) based on IOTF criteria. The controls are adolescent characteristics (age, gender, AVM consumption, meal frequency, health-related quality of life, number of friends and time spent together) and mother and family characteristics (age, occupation, BMI and household income). Dependent on regression type, we use country dummies as fixed or random effects. Robust standard errors are in parentheses $(S E) ; 95 \%$ confidence intervals $(C I)$ are in brackets.

${ }^{*} p<0.05$.

${ }_{* *}^{*} p<0.01$

*** $p<0.001$. 
Table A4

OLS/MMGLM estimates of peer effects on adolescent weight status

\begin{tabular}{|c|c|c|c|}
\hline Variable & OLS & OLS & MMGLM \\
\hline & (1) & (2) & (3) \\
\hline \multicolumn{4}{|c|}{$B M I(\mathrm{z}$-score $)$} \\
\hline Average peer BMI & $0.292^{* * *}$ & $0.116^{*}$ & $0.130^{* * * *}$ \\
\hline$S E$ & $(0.055)$ & $(0.058)$ & $(0.037)$ \\
\hline $95 \% C I$ & {$[0.185,0.399]$} & {$[0.002,0.230]$} & {$[0.058,0.202]$} \\
\hline$N$ & 581 & 581 & 581 \\
\hline $\mathrm{R}^{2}$ & 0.050 & 0.312 & \\
\hline \multicolumn{4}{|c|}{ Waist circumference (z-score) } \\
\hline Average peer waist circumference & $0.237^{* * *}$ & $0.119^{*}$ & $0.114^{* * *}$ \\
\hline$S E$ & $(0.052)$ & $(0.054)$ & $(0.013)$ \\
\hline $95 \% C I$ & {$[0.134,0.339]$} & {$[0.013,0.225]$} & {$[0.089,0.139]$} \\
\hline$N$ & 580 & 580 & 580 \\
\hline $\mathrm{R}^{2}$ & 0.033 & 0.257 & \\
\hline \multicolumn{4}{|c|}{ Body fat (z-score) } \\
\hline Average peer body fat & $0.381^{* * *}$ & $0.160^{* *}$ & $0.176^{* * *}$ \\
\hline$S E$ & $(0.050)$ & $(0.060)$ & $(0.031)$ \\
\hline $95 \% C I$ & {$[0.283,0.478]$} & {$[0.041,0.278]$} & {$[0.115,0.237]$} \\
\hline$N$ & 579 & 579 & 646 \\
\hline $\mathrm{R}^{2}$ & 0.088 & 0.300 & \\
\hline Controls & No & Yes & Yes \\
\hline
\end{tabular}

Notes: The dependent variables are individual z-scores of BMI, waist circumference (WC) and body fat (BF) based on IOTF criteria. The controls are adolescent characteristics (age, gender, AVM consumption, meal frequency, health-related quality of life, number of friends and time spent together), mother and family characteristics (age, occupation, BMI and household income) and peers' mother characteristics (age, occupation and BMI). Dependent on regression type, we use country dummies as fixed or random effects. Robust standard errors are in parentheses $(S E) ; 95 \%$ confidence intervals $(C I)$ are in brackets.

${ }^{*} p<0.05$.

${ }^{* *} p<0.01$

${ }^{* * *} p<0.001$. 